\section{Significação como possível caminho inovador para projetos de Design de Ambientes}

Simone Abreu *

Resumen: Este artículo busca discutir un camino posible y estratégico de diseño de interiores desde la perspectiva de la significación, presentada por la innovación guiada por el diseño. El ambiente tiene dos dimensiones a considerar: las objetivas, observables, y las subjetivas que son aquellas relacionadas al sistema de significación. Este artículo trae resultados de investigación realizada con los diseñadores docentes de la Escuela de Diseño, analizando los principales aspectos abordados en los proyectos. ¿Cuál es el aspecto de mayor relevancia para esos docentes del proyecto? Ante el escenario complejo actual donde el diseño interactúa cada vez menos con disciplinas objetivas y exactas, y más con los factores estésicos y psicológicos, ¿Cuál sería el camino innovador y estratégico para el diseño de ambientes? La innovación guiada por el diseño abre el camino para una innovación radical, abordando el significado que los productos presentan como centro de esa innovación. Se espera que este artículo pueda contribuir positivamente a una nueva mirada proyectiva, que contribuya con el bienestar del usuario.

Palabras clave: Diseño de interiores - Significado - Estrategia - Innovación.

[Resúmenes en inglés y portugués en las páginas 124-125]

${ }^{(*)}$ Graduada em Design de Ambientes, Especialista em Educação e Mestre em Design. Docente no Curso de Design de Ambientes da Escola de Design - UEMG. Linha de pesquisa - Projeto para o desenvolvimento econômico.

\title{
Introdução
}

Esse artigo tem o propósito de apresentar discussões sobre os aspectos subjetivos em projeto de ambientes; a importância desses aspectos em projeto e caminho possível para desenvolver inovação à partir da estratégia da significação, trazida pela Inovação Guiada pelo Design, a partir dos pressupostos apontados por Roberto Verganti (2009).

O design de ambientes é uma atividade de caráter multidisciplinar responsável por identificar e solucionar problemas oriundos das relações entre o homem e o espaço -tanto internos quanto externos, residenciais, empresariais, institucionais, industriais ou efêmeros, arquitetônicos ou não arquitetônicos, incluindo ambientes virtuais e de transporte- tendo o usuário como foco de projeto e considerando os aspectos funcionais, estéticos e simbóli- 
cos do contexto social-econômico-cultural em que atua, de modo a resultar em ambientes confortáveis e eficientes às demandas estabelecidas.

Para atingir o resultado esperado, os designers de ambientes necessitam de estar conscientes dos aspectos objetivos de projeto que são: funcionalidade, segurança, técnica, tecnologia, custo dentre outros e dos aspectos subjetivos como: estima, desejos, emoções, símbolos, dentre outros. Diante da complexidade trazida pela globalização, onde o cenário antes mais lógico e previsível passa a ser demandado por questões distintas e subjetivas ampliando a importância de considerar em projeto as relações afetivas, psicológicas e emocionais, algumas questões de pesquisa foram levantadas:

- Como então os designers de ambientes estão, na atualidade, direcionando seus projetos?

- Quais aspectos têm sido de maior relevância para projeção de ambientes?

- Qual caminho possível e inovador para auxiliar os designers de ambientes em projetos?

Esse artigo está estruturado em cinco partes. Na introdução apresenta o objetivo e as questões que incentivam a pesquisa. A segunda discute o que seja ambiente, espaço e lugar por vários estudiosos, conduzindo o entendimento dos diversos aspectos a serem considerados em projeto. Na sequência apresenta os resultados de questionário destinado aos docentes da Escola de Design, da Universidade do Estado de Minas Gerais, Brasil, objetivando entender as relações da subjetividade e projeto de ambientes. Os resultados aqui apresentados demonstram como os docentes interagem com a subjetividade em projeto e por consequência o aspecto relevante que consideram e ensinam. A quarta seção discorre sobre a temática recente da Inovação Guiada pelo Design trazida por Verganti. Apresenta o conceito e qual a maneira possível de conseguir inovação através da interpretação dos significados. Por fim, aponta caminhos para as questões levantadas e contribuições para projetos e ensino do design de ambientes.

\section{Ambiente e significado}

Segundo Cardoso (2004) e Forty (2007), organizar os espaços do cotidiano, tanto interno como externos, foi uma necessidade acontecida na era moderna. A consciência da sociedade de um mundo privado e público inicia-se nessa época: com a centralização do homem; com as grandes descobertas; com o advento do capitalismo e com o nascer da classe burguesa. Possibilitou, então, o desejo por móveis e pela divisão dos espaços internos de acordo com sua função. Mais tarde, com a urbanização, no século XIX, no qual o espaço do trabalho se desvinculou do espaço da casa, os lares passaram a ser considerados e ornados em demasia, para serem diferenciados dos ambientes corporativos. No contexto das décadas de 40 e 50 do século passado, ampliaram-se as possibilidades de aquisição de artefatos, de móveis e de eletrodomésticos para o consumo, evidenciando a extrema preocupação com a aparência e eficiência nos ambientes habitados, evidenciando não mais um desejo de arranjo dos espaços, mas uma necessidade, ditada pela então complexidade da modernização.

O designer de ambientes passa a ser, então, o profissional responsável por identificar e solucionar problemas oriundos das relações entre o homem e o espaço. Por estar inserido na 
área das ciências sociais aplicadas, o designer de ambientes compromete-se com a função social, contribuindo para o bem-estar e a qualidade de vida de seus usuários. Para atender ao bem-estar das pessoas, o ambiente tem que ser capaz de transmitir aos seus habitantes o sentimento de pertencimento e senso de identidade.

O ambiente construído, segundo Malard (2001, p. 1), é um sistema de comunicação, pois através dele "são veiculadas diversas manifestações do imaginário coletivo ou, diretrizes para o comportamento social". A estrutura do arranjo dispõe e combina objetos de forma a obter um conjunto funcional capaz de comunicar valores sociais. Existe no arranjo dos ambientes uma combinação tal de objetos, materiais, formas, cores, texturas que traz à tona a comunicação de valores da cultura que o gerou. Malard (2001, p. 5) afirma que a ambiência possibilita duas dimensões a serem consideradas:

- Objetivas: são aquelas que dizem respeito às sensações corpóreas como conforto acústico, térmico, lumínico e dimensional. É a dimensão entendida como uma harmonia biológica com o ambiente -isolamento acústico, conforto térmico, adequado nível de luminamento, medidas e proporções adequadas- possuindo também certo grau de subjetividade. - Subjetivas: são aquelas relacionadas com o sistema de significação dos objetos e são estritamente dependentes dos padrões culturais.

A forma com que o designer percebe o ambiente, como se constroem os espaços e como estes se tornam lugares ou não lugares influenciará numa série de decisões projetuais, desde sua configuração até mesmo na escolha de materiais e artefatos adequados. A importância desse conhecimento atribuirá valor aos projetos de ambientes, principalmente no que diz respeito ao entendimento da influência do sujeito no ambiente e este sobre o sujeito. Um exemplo (Ver Figura 1) é o ambiente projetado para o Museu de Comics e Animação na China. Possui uma arquitetura enorme em formato de balões de fala. $\mathrm{O}$ museu será uma biblioteca e um acervo de produções nas áreas de comics e animações do país. A forma arredondada e o ambiente interior possuem formas, cores e texturas que significam, envolvendo o usuário para o mundo de animação.

Christian Schmid (2012) explana a respeito dos fundamentos de Lefebvre sobre o que seja espaço. Lefebvre propõe uma teoria que entende o espaço como essencialmente ligado à realidade social; o espaço não existe por si mesmo, ele é produzido por seres humanos que constroem nele sua vida. Esse 'social' não é corpo e matéria numa soma de ações e práticas, mas seres humanos vivos, construídos de corpo, pensamento, imaginação, sensibilidade, ideologia e que se relacionam entre si pelas atividades e práticas cotidianas.

E como o espaço social é produzido? Para Lefebvre a produção do espaço pode ser dividida em três dimensões ou processos dialeticamente interconectados:

- O espaço ' percebido' que é aquele reconhecido pelos sentidos, visão, audição, olfato, tato e paladar e relaciona-se diretamente com a materialidade dos elementos que o constituem;

- O espaço percebido não pode ser reconhecido sem ter sido 'concebido' em pensamento. Após percebido, passa a ser concebido, que presume um ato de pensamento ligado à produção do conhecimento;

- O espaço 'vivido' é a experiência prática do espaço. 


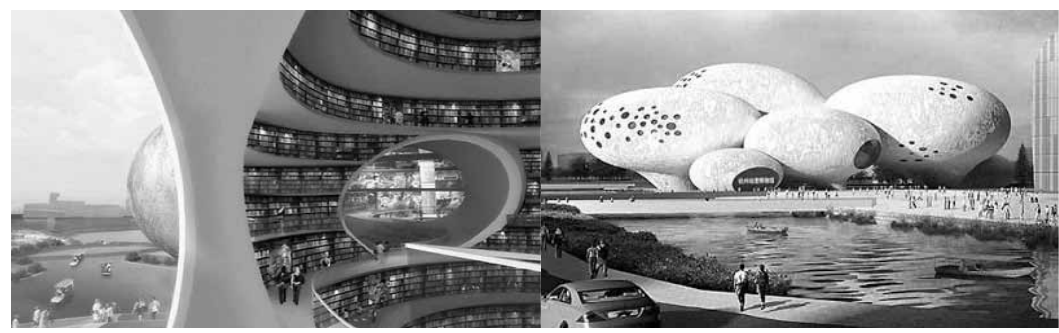

Figura 1.

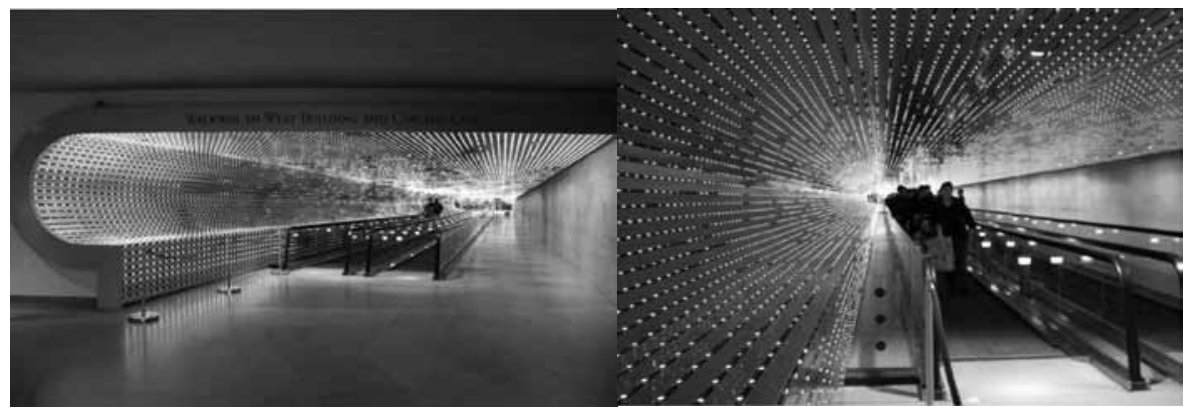

Figura 2.

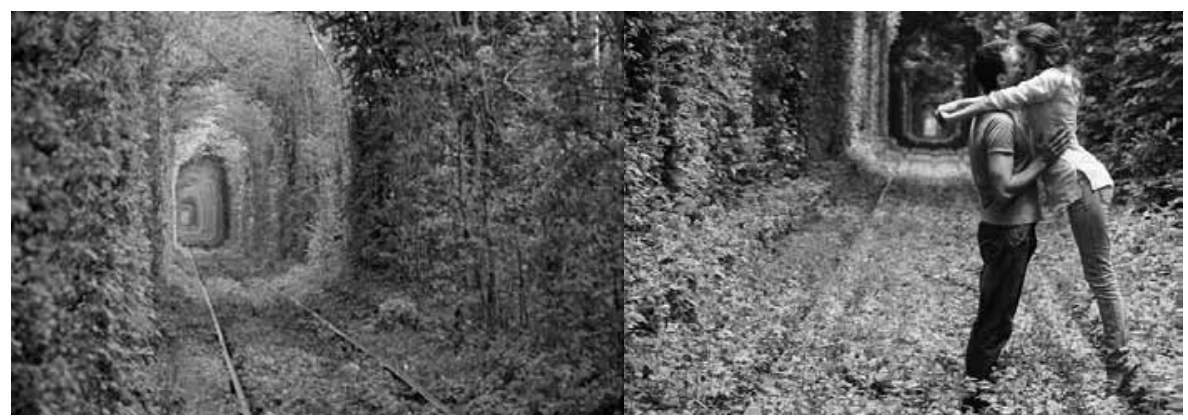

Figura 3.

Figura 1. Museu Chinês de Comics e Animação. Fonte: eutresvezes.blogspot.com.br. Figura 2. Museu San Jose de Arte. Fonte: jozefpronek.livejournal.com. Figura 3. The tunnel of love, Ukraine (O Túnel do Amor). Fonte - placestoseeinyourlifetime.com 
"Essa tríade é, ao mesmo tempo, individual e social; não é somente constitutiva da autoprodução do homem, mas da auto-produção da sociedade. Todos os três conceitos denotam processos ativos individuais e sociais ao mesmo tempo". (Schmid, 2012, p. 102) O núcleo da teoria da produção do espaço se identifica em três momentos: produção material, de conhecimento e de significados. Esse pensamento desenvolvido por Lefebvre nos faz compreender que o espaço não é vazio, fechado por paredes, ventilado por janelas e acessado por uma porta, protegido pelo teto e pavimentado por piso, aguardando ser 'preenchido' por alguém. O espaço é uma construção das pessoas que o habitam, que realizam suas atividades físicas, de trabalho, ou de lazer. É algo animado, envolvido de história, relações interpessoais, cultura e sentimento de pertencimento. É construído por comunicação, confronto, linguagem, discurso, signos, troca mental para que a edificação material seja realizada. E mesmo assim, depois de materialmente construído, será vivenciado, experimentado e tomado novamente como reflexão para construção de novos ambientes. Compreende-se um ciclo vivo e complexo que não pode ser simplesmente planejado sem um nível de percepção, fundamentação e experimentação. O exemplo sugerido na Figura 2 é apresentado pelo ambiente criado por Leo Villareal no Museu San Jose de Arte na Califórnia, Estados Unidos. Uma esteira rolante assumiu nova dimensão com a adição de LED produzindo uma sensação de futuro que faz sentido e fornece experiência ao usuário. Para Cavalcante e Nóbrega (2011), espaço é entendido como uma área geométrica concreta ou um englobante dentro do qual se situam todos os espaços particulares; é a base para organização, indispensável à criação de distancias e delimitações. O espaço é algo exterior em relação ao indivíduo, sendo, desta forma, neutro, sem significado. Lugar é o espaço que identificamos. É onde estabelecemos parada; seus limites são definidos. "É um espaço ao qual se atribui significado e que ganha valor pela vivência e pelos sentimentos. Lugar é o espaço com o qual se estabelece relação" (Cavalcante; Nóbrega, 2011, p. 182). Segundo Bachelard (1958, p. 47), "a relação da pessoa com um espaço é que permite sua transformação em lugar”. O espaço geométrico é neutro, mas ganha significado quando é inserido nele o homem. O espaço passa a ser reconhecido, ganha importância quando os sentimentos e valores atribuídos a ele, que são trazidos pelo homem, adquirem assim identificação. De acordo com Tuan (2013), o significado de espaço se funde com o de lugar. Para o autor, "o que começa como espaço indiferenciado transforma-se em lugar à medida que o conhecemos melhor e o dotamos de valor" (Tuan, 2013, p. 14). Ele ainda comenta que os lugares são núcleos aos quais atribuímos valor e onde as necessidades biológicas de comida, água, descanso e procriação são satisfeitas. O lugar pode ser formado em um breve espaço de tempo ou mesmo em anos. Para que o espaço se torne lugar, é decisivo senti-lo, não depende do tempo investido ou do tipo de uso, mas sim da impressão causada pela relação do indivíduo com o ambiente e do tipo de vínculo gerado. "É uma mistura singular de vistas, sons e cheiros, uma harmonia ímpar de ritmos naturais e artificiais [...] Sentir um lugar é registrado pelos nossos músculos e ossos" (Tuan, 2013, p. 224). Viver, sentir, usar, perceber, relacionar são processos para construção de um lugar, que vai além de um espaço físico. Um exemplo (Ver Figura 3) de lugar poderia ser analisado pelo Túnel do Amor, em Ukraine na Ucrânia. Ambiente produzido pelo envolvimento das árvores ao trem que passa três vezes ao dia. O lugar é visitado nos momentos que o trem não transita, e transmite um envolvimento particular. É o espaço transformando-se em lugar, uma 
mistura ímpar de vistas, sons e cheiros que vai muito além do tangível e adquirindo valor. É empolgante perceber a construção de um ambiente não só pelo seu arranjo material, sua função, sua estética, mas pela riqueza dos valores subjetivos que diferenciam cada projeto estabelecido. Cada material, cada objeto está carregado por um olhar de mundo diferenciado. É emergente também que os designers de ambientes compreendam os valores atribuídos para construção de ambientes para que, considerados, transformem espaços em verdadeiros lugares, sensivelmente identificados com o usuário. Como, então, os designers vem projetando seus ambientes? Consideram mais os aspectos objetivos e tangíveis do espaço ou procuram também dar relevância aos aspectos intangíveis atribuindo significado e valor aos ambientes?

\section{Pesquisa com os profissionais a respeito da prática projetual de ambientes}

Essa pesquisa foi direcionada aos profissionais do Design de Ambientes de formação superior em Design de Ambientes, Design de Interiores ou Decoração e atuantes na área como docentes da Escola de Design em Belo Horizonte. O questionário foi enviado em formato digital, respondido por 13 docentes e as respostas foram analisadas de forma quantitativa. Teve como objetivo verificar a maneira de projetar; discernir a importância que esses profissionais consideram ao projetar ambientes - aspectos objetivos ou subjetivos; entender como são efetuadas as escolhas de materiais e objetos no planejamento de ambientes e saber a relevância do uso de um método que abarcasse os aspectos subjetivos em projeto. Para esse artigo, foi selecionado os resultados que dizem respeito a importância dos aspectos objetivos e subjetivos em projeto por parte dos designers. A relevância dessas respostas, para esse artigo, está em avaliar se os designers de ambientes compreendem o ambiente como espaço físico, considerando os aspectos objetivos ou se agregam os aspectos subjetivos em projeto.

\subsection{Resultados}

Os resultados aqui expostos são de profissionais de $100 \%$ do sexo feminino. Faixa etária entre 41 a 50 anos de idade, correspondendo a $46.15 \%$. O perfil acadêmico é caracterizado por especialistas, observado nos $46.15 \%$ das respostas. O tempo médio de experiência profissional está abaixo de 10 anos, correspondendo a $46.15 \%$, seguido ficam os de entre 20 e 30 anos de profissão. O número de ambientes projetados está acima de 500 ambientes, ocupando também o mesmo patamar estão aqueles que não conseguem mensurar o número de ambientes projetados, correspondendo ambos a 30,76\%.

Perguntou-se aos profissionais sobre o grau de importância que atribuem aos aspectos subjetivos e objetivos ao elaborarem projetos de design de ambientes. Foram dispostos vários aspectos relevantes em um projeto, não distinguindo, no entanto, se eram objetivos ou subjetivos. A maioria dos participantes, $92,31 \%$ responderam que o aspecto mais importante em projeto é o da funcionalidade, seguindo o da segurança com $84,62 \%$, ambos 


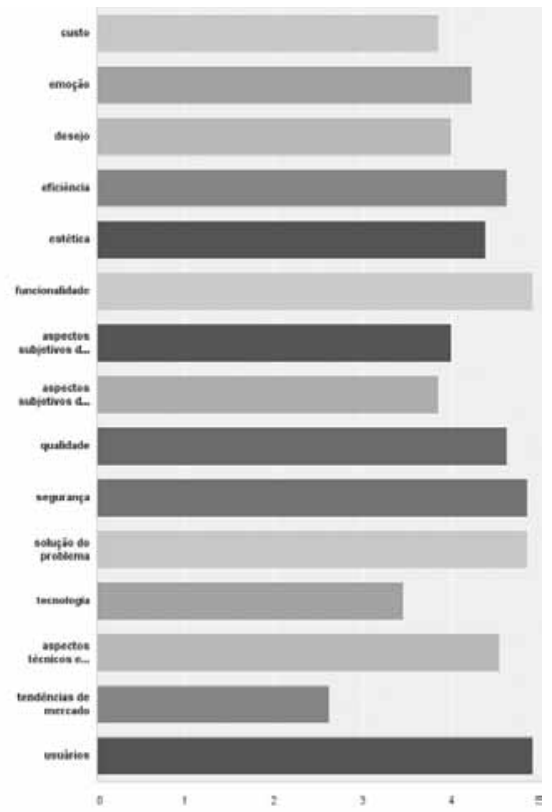

Figura 4 .

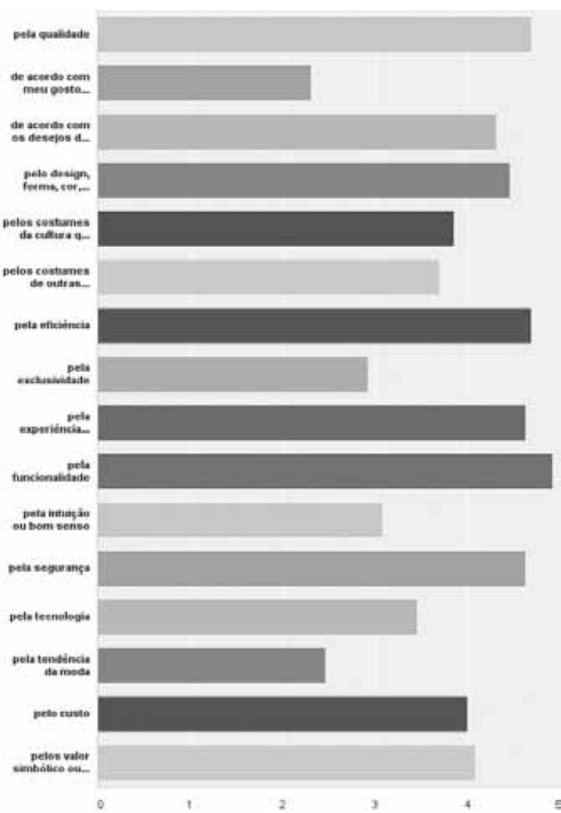

Figura 5.

Figura 4. Grau de importância ao elaborar projetos. Fonte: Resultados do questionário. Figura 5. Fator de escolha dos materiais e objetos. Fonte: Resultados do questionário.

são aspectos objetivos, como mostra a Figura 4. Além disso, os aspectos objetivos como qualidade, eficiência e os técnicos ficam à frente dos aspectos subjetivos como por exemplo emoção e desejo. Conclui-se então, que apesar da solução de problema e o usuário serem relevantes também nessa questão, os profissionais não interpretam os aspectos subjetivos como fator de solução projetual.

A objetividade fica também nítida na resposta à pergunta aos profissionais que indaga como eles escolhem os materiais e objetos após conceituar um ambiente: $92.31 \%$ responderam que escolhem pela funcionalidade. Entretanto $76.92 \%$ responderam que escolhem pela experiência prazerosa do usuário - linha vermelha da figura (Ver Figura 5).

Portanto, se observarmos que os aspectos, tais como: eficiência; qualidade e segurança são percentualmente mais escolhidos que os aspectos intangíveis como: valor simbólico; desejos do usuário; costumes da cultura; percebe-se que a interpretação de experiência prazerosa pelos profissionais talvez atravesse pelos aspectos objetivos. 


\begin{tabular}{|l|c|c|}
\hline \multicolumn{1}{|c|}{ referência para escolha } & resposta & \\
\hline Indicação de outros profissionais & 4 & $30,77 \%$ \\
\hline blogs & 0 & $30,76 \%$ \\
\hline $\begin{array}{l}\text { Revistas especializadas da área do } \\
\text { design }\end{array}$ & 7 & $53,85 \%$ \\
\hline $\begin{array}{l}\text { Livros da área do design - teóricos e } \\
\text { práticos }\end{array}$ & 3 & $38,46 \%$ \\
\hline Lojas especializadas & 13 & $100 \%$ \\
\hline Amostras físicas & 12 & $92,31 \%$ \\
\hline websites & 8 & $61,54 \%$ \\
\hline outros & 0 & $0,00 \%$ \\
\hline \multicolumn{2}{|l|}{} \\
\hline
\end{tabular}

Figura 6.

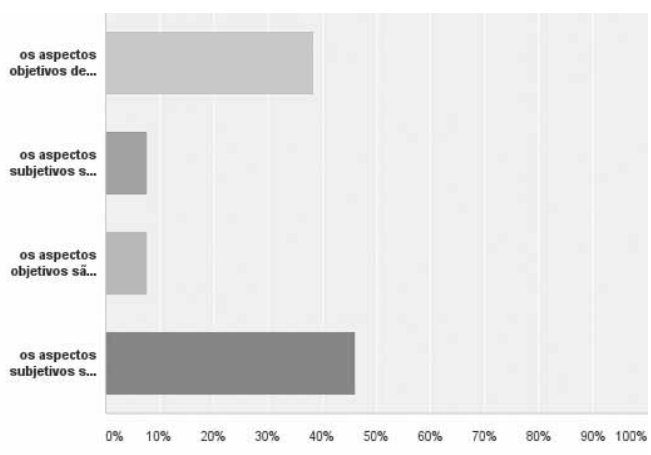

Figura 7.

Figura 6. Fonte de escolha dos materiais e objetos. Fonte: Resultados do questionário. Figura 7. Fonte de escolha dos materiais e objetos. Fonte: Resultados do questionário.

Outro fator característico da objetividade em projetos é que por unanimidade, isso é , $100 \%$ dos questionados responderam que a fonte de busca de materiais o objetos são nas lojas especializadas, veja na Figura 6. Há uma disposição de que lojas especializadas em materiais e objetos para ambientes comercializarem o que está na moda e/ou o que o mercado deseja que o consumidor compre. Essa realidade acaba por não considerar a individualidade do usuário, seus desejos e emoções, fazendo com que ambientes tenham materiais e objetos igualitários. A igualdade de ambientes transita pela interpretação que não se busca um diferencial para o usuário. Portanto, se os profissionais buscam suas escolhas nas lojas, eles não consideram os aspectos subjetivos como prioridade projetual. 
A maioria dos questionados, $46.15 \%$, dizem que empregam os aspectos subjetivos em projeto, mas são difíceis de serem medidos, por isso são aplicados através de decisões intuitivas ou de bom senso - linha cinza da Figura 7, e ainda 38,46\% consideram os aspectos objetivos como realidade projetual, pelo fato desses possuírem possibilidade de quantificação - linha verde claro da Figura 7. Essas respostas estão coerentes com as análises anteriores, onde os aspectos objetivos são os de maior relevância projetual.

Conclui-se que a maioria dos respondentes desse questionário consideram os aspectos objetivos como de maior relevância tanto projetual como na escolha de materiais e objetos e a funcionalidade é o aspecto mais considerado. Percebem a subjetividade como necessária em projeto, entretanto manuseia esses aspectos de forma intuitiva ou pelo bom senso e pelas tendências do mercado, isso é, além de pouco fundamentada, consideram pouco as questões individuais do usuário, até mesmo pelo fato de não saberem lidar com elas.

Se os ambientes são construídos através de relações humano/espaço nos seus aspectos subjetivos e objetivos; se o ser humano influencia o ambiente tanto quanto o ambiente o influencia; se o homem é dotado de cultura e se os materiais e objetos são portadores de significados e por fim, os significados são percebidos pelos sentidos humanos de forma intangível, os resultados aqui considerados nesse questionário denotam que os ambientes não estão sendo integralmente planejados, de acordo com esses profissionais designers questionados, para atender aos usuários, perdendo com isso na identidade, portanto na eficiência, na sustentabilidade, na inovação e por fim, na qualidade de vida. Existe caminho possível para projetos de design que abarque questões subjetivas e que possa contribuir na construção de ambientes menos objetivos e mais significativos?

\section{Inovação guiada pelo Design}

Os tempos vividos pela sociedade atual são profundamente marcados pelo impacto da globalização que trouxe interação e aproximação de pessoas; uma interligação com o mundo e uma dinamização da economia, política, sociedade e cultura. O cenário, de acordo com Moraes (2011), antes bem mais previsível, lógico, concreto e estático, passa para dinâmico e complexo. Cardoso (2012) salienta que mudanças importantes vem ocorrendo na complexidade contemporânea, no que diz respeito à maneira de experimentarmos o tempo e espaço, que possibilita transições muito rápidas entre o material e o imaterial, "a agilidade com que o imaterial pode ser capturado e transmitido torna supérflua sua materialização" (Cardoso, p. 40, 2012). Essa questão, nos leva a compreender que chegará o momento em que não saberemos mais o que seja material ou imaterial e as premissas do design antes tão consideradas, como o aspecto objetivo da forma segue a função, poderá estar com seus dias contados. Diante desse contexto distinto, múltiplo e complexo, será exigido muito mais das habilidades dos profissionais para a manipulação das informações, para a interpretação dos fatos e para a tomada de decisão.

Essa transformação também atravessa a profissão do design, que passou a ter a necessidade notória de valorizar os conteúdos subjetivos ou imateriais, as relações afetivas, psicológicas e emocionais. Esses conteúdos devem ser mais contemplados nos produtos, sejam eles gráficos, produto, moda ou ambientes para obterem maior significado, isto é, maior 
identidade com o usuário. Encontrar uma nova maneira de projetar, de solucionar problemas, de apresentar novas formas tangíveis daquilo que vem das emoções, desejos e afeto do usuário é para o que o designer na atualidade deve estar preparado. De acordo com Moraes (2011), "hoje a necessidade de se dar forma a um produto é mais uma questão semântica, comunicativa e ergonômica do que tecnológica” (Moraes, p. 35 , 2011). Como então poderíamos tratar essas questões no design? Qual poderia ser a maneira de trazer maior sentido aos produtos? Existe alguma discussão na atualidade que possa contribuir para esse novo contexto?

A Inovação Guiada pelo Design é uma teoria que vem tomando corpo na atualidade e procura discutir e propor uma nova leitura para a construção de produtos. Segundo Verganti (2009), um dos autores que trata dessa temática, as pessoas não usam produtos ou serviços pensando apenas na sua utilidade, isso é, nas questões somente objetivas de projeto, olham para além de características, funções e desempenho. O que emerge nessa teoria é a investigação de outra importante parte da construção de um produto que é a dimensão dos símbolos, identidade e emoções, enfim dos significados que as pessoas destinam às coisas e com isso buscar novas interpretações do significado. "A dialética não é somente entre função e forma, mas entre função e significado" (Verganti, 2009).

Verganti (2009) continua dizendo que as empresas são realmente inovadoras quando procuram saber do tipo de experiência que as pessoas gostariam de ter, para que possam avaliar o significado do produto e com isso, interpretar novos significados. De acordo com os psicólogos Mihalyi Csikszentmihalyi e Eugenie Rochberg-Halton citados por Verganti (2012), "pessoas assimilam objetos em suas vidas privadas e lhes dão significados simbólico como expressões de suas experiências" (Verganti, 2009).

Isso quer dizer que para saber dos significados simbólicos necessita-se saber das experiências do usuário. Além disso, o ser humano passa a vida inteira à procura de significados, ele convive com os filhos, cônjuge e colegas, depois de um segundo, não poderia tornar-se desumano ao entrar em um carro e dirigi-lo, isso é, os objetos e ambientes são extensão do ser humano e por isso devem agregar os mesmos significados.

A Inovação Guiada pelo Design objetiva uma inovação radical do significado, isto é uma proposta que possa modificar o contexto. Investe em saber das experiências que as pessoas poderiam desejar, partindo de pesquisas aprofundadas sobre tendências socioculturais, estilo de vida e evolução tecnológica, no que diz respeito aos fatores simbólicos, emocionais e intangíveis. A partir disso, interpreta novos significados, modificando paradigmas culturais dominantes, buscando enfim a inovação. Essa proposta partilha conhecimentos através de experiências exploratórias ao invés de criatividade espontânea. Inovações clássicas são concebidas principalmente a partir de fatores tangíveis como tecnologia, utilidade, desempenho e função. Enfim, o contexto atual complexo pede novas leituras dos produtos, por isso necessitam inovações radicais e que abranjam as questões estésicas.

Um dos exemplos de Verganti (2009) é da Artemide, empresa italiana, fabricante de lâmpadas. Através da Lâmpada Metarmofose -lâmpada de assoalho que permite atmosferas de luz infinitas- que ao invés de propor inovação somente pela tecnologia ou mesmo através de uma interpretação melhorada, buscou emitir uma luz "humana": a luz que faz você se sentir melhor, enfim utilizou da inovação radical quando interpretou o significado da luz para as pessoas. O usuário da Metarmofose usa um dispositivo de controle remoto, 
gerenciando dez atmosferas que altera a luz ambiente colorindo de acordo com a disposição e situação, desde relaxamento até interatividade. Esse projeto não é apenas forma e estilo e sim significado.

Esse recente estudo incorpora de maneira integradora o design, administração e marketing e outras áreas humanas como a psicologia e antropologia, buscando uma nova maneira de perceber novos significados. O ambiente habitado não é o produto de design que Verganti (2009) investiga como exemplo em seu livro, mas posicionando-se o ambiente como uma comunicação de produtos, ele poderá ser considerado em todos os objetivos da inovação guiada pelo design e os designers de ambientes poderão utilizar das mesmas decisões para planejar espaços inovadores e radicais em seus conceitos.

\section{Considerações finais}

O maior desafio para o Design de Ambientes na atualidade é fazer com que ambientes sejam projetados de forma a considerar os aspectos de significação, visando espaços de maior identidade. Apesar do reconhecimento desses aspectos em ambientes projetados, ainda na prática estão sendo esboçados primordialmente pelo olhar da função. A Inovação Guiada pelo Design poderá ser uma nova proposta de inovação através da compreensão dos significados dos produtos.

Para vários estudiosos como Malard (2001); Schmid (2012); Cavalcante e Nóbrega (2011), Bachelard (1958) e Tuan (2013) o ambiente construído é dotado de significado a partir do momento que é organizado por materiais e objetos atribuídos de sentido. Porém, de acordo com a pesquisa realizada com os docentes da Escola de Design, a realidade ainda é que, ambientes estão sendo projetado primordialmente por uma abordagem objetiva, tais como funcionalidade, eficiência, segurança e técnica. Essa abordagem pode auxiliar na inovação incremental, portanto dificulta as possibilidades de uma inovação radical, isso é, modificação na estrutura cultural dominante, que amplia o olhar compreensivo dos reais significados que os usuários dão às coisas.

A Inovação Guiada pelo Design é uma temática atual que visa saber de forma estratégica das experiências do usuário para interpretar novos significados, portanto garantir inovação radical. Poderíamos compreender que um profissional de ambientes inovador será aquele que souber projetar ambientes considerando as experiências que os usuários gostariam de ter, interpretar essas experiências, com o intuito de alterar significados, portanto gerar novos resultados. Então, se os projetos atualmente estão sendo alicerçados, em sua maior parte, pelas questões de funcionalidade, qualidade e segurança, além de estarem diante de pouca possibilidade de atender plenamente ao usuário, os designers estão perdendo a oportunidade estratégica de investir na criação de ambientes inovadores, isso é, ambientes com novos conceitos e principalmente que atenda ao princípio de que ambientes são dotados de valores de estima, de desejos e de símbolos.

Essa abordagem irá exigir muito mais dos designers de ambientes nas interpretações do intangível, incluindo uma visão sistêmica para esse processo. Seria valoroso, talvez, propor no briefing questões direcionadas às emoções, desejos e experiências do usuário, objeti- 
vando perceber melhor quem é esse homem que irá usufruir desse espaço, culturalmente, socialmente e psicologicamente falando.

Nesse sentido, por fim, reforça-se a importância de trazer para o ensino uma análise crítica do que seja a projeção de ambientes nos seu aspecto intangível. Como a análise realizada dos questionários procederam das respostas dos docentes, percebe-se a necessidade reflexiva desses profissionais que ensinam projeção de ambientes, que estão priorizando questões tangíveis em projeto. As disciplinas de Práticas Projetuais, Metodologia Aplicada ao Projeto de Design e Estudos de Mercado devem incluir em seus conteúdos possibilidades de interpretação das experiências do usuário, análise de valores do usuário e suas necessidades intangíveis, dentre outros.

\title{
Referências
}

Bachelard, G. (1958). Poética do espaço. Rio de Janeiro: Martins Fontes.

Cardoso, R. (2004). Uma introdução à história do Design. São Paulo: Blucher.

Cardoso, R. (2012). Design para um mundo complexo. São Paulo: Cosacnaify.

Calvalcante, S.; Nóbrega, L. (2011). Temas básicos em psicologia ambiental. Petrópolis: Vozes. Forty, A. (2007). Objetos de desejo: design e sociedade desde 1750. São Paulo: Cosac Naify.

Lefebvre, H. (1977). De l'État, tome III: le mode de production étatique. Paris: Union Générale d'Editions.

Malard, M. (2001). Os objetos do quotidiano e a ambiência. In: Encontro Nacional de Conforto e Ambiente. Belo Horizonte, MG. Recuperado de http://www.arq.ufmg.br/eva/ docs/art014.pdf.

Moraes, D.; Dias, R.; Conselho, R. (Ed.). (2011). Cadernos de estudos avançados em design: método. Barbacena: EdUEMG.

Schmid, C. (2012). A teoria da produção do espaço de Henri Lefebvre: em direção a uma dialética tridimencional. GEOUSP - espaço e tempo, N³2, pp. 89-109.

Tuan, Y. (2013). Espaço e lugar: a perspectiva da experiência. Tradução de Lívia de Oliveira. Londrina: Eduel.

Verganti, R. (2009). Design-driven innovation: changing the rules of competition by radically innovating what things mean. Boston: Harvard Business Press.

\begin{abstract}
Abstrat: This article discusses a possible and strategy way of projection of the environments from the perspective of meaning, presented by design-driven innovation. The environment has two dimensions to consider what are the objective, observable and subjective which are those related to the system of meaning. This article presents results of research carried with teachers designers of the Escola de Design, analyzing the main issues addressed in projects. What aspect of greatest importance for these teachers of the project? In today's complex scenario where the design interacts less and less objective and exact disciplines and more with sensitive and psychological factors, which would be the innovative and strategic path for projection environments? Design-driven innovation
\end{abstract}


paves the way for a radical innovation, addressing the meaning that the products are at the center of this innovation. It is hoped that this article will contribute positively to a new look projectual contributing to user welfare.

Key words: Environment Design - Meaning - Strategy - Innovation.

Resumo: Este artigo busca discutir um caminho possível e estratégico de projeção de ambientes pelo viés da significação, apresentada pela inovação guiada pelo design. O ambiente possui duas dimensões a serem consideradas que são as objetivas, observáveis e as subjetivas que são aquelas relacionadas ao sistema de significação. Esse artigo traz resultados de pesquisa realizada com os designers docentes da Escola de Design, analisando os principais aspectos abordados em projetos. Qual o aspecto de maior relevância para esses docentes em projeto? Diante do cenário complexo atual onde o design interage cada vez menos com disciplinas objetivas e exatas e mais com os fatores estésicos e psicológicos, qual seria o caminho inovador e estratégico para projeção de ambientes? A inovação guiada pelo design abre caminho para uma inovação radical, abordando o significado que os produtos apresentam como centro dessa inovação. Espera-se que esse artigo possa contribuir positivamente para um novo olhar projetual colaborando para o bem-estar do usuário.

Palavras chave: Design de Ambientes - Significado - Estratégia - Inovação- 